\title{
Structural Analysis of Carbon Fiber-reinforced Thermoset Composite
}

\author{
L. BARREIRO ${ }^{1}$, P. ARAÚjO² ${ }^{2}$ J. TELES 3 \\ 1University of Debrecen, Faculty of Engineering, Department of Mechanical Engineering, larissabarreiro@mailbox.unideb.hu \\ 2University of Debrecen, Faculty of Engineering, Department of Mechanical Engineering, paulovictor.sa@mailbox.unideb.hu \\ 3University of Debrecen, Faculty of Engineering, Department of Mechanical Engineering, john.teles@mailbox.unideb.hu
}

Abstract: Materials are usually stronger in fibrous form than in bulk form. Composites are made from bonding two materials, where the reinforcement contributes with the outstanding natural properties and the matrix supports the fibers by transferring the loads between them, besides protecting the fiber from the environment hazards. Consequently, creating a strong composite that can be used in various applications and situations. In this academic work it is going to be analyzed how the composite made from carbon fiber and epoxy thermoset matrix behaves in specific situations, by making them in two different manufacturing methods. In addition, the analysis is going to be made in the laboratories of the university and then compared with computer analysis. So, the first phase of this academic work is being presented and highlighted below.

\section{Introduction}

A large number of modern technologies requires materials with different combinations of properties that cannot be found by the conventional metal alloys, ceramics, and polymeric materials [1]. In general, it is considered a composite the combination of two or more elements, made artificially, that results in a new one with better properties than those of the individual components used alone [2]. However, a material is a composite only when the constituent phases have different physical or chemical properties [3]. Composites are commonly designed with a particular use in mind, for example high strength and stiffness combined with low density [1], [4]. In a composite, one phase, called matrix, is usually continuous and surrounds the other phase, or phases, termed reinforcement or reinforcing material. Commonly, the reinforcement is harder, stronger and stiffer than the matrix [1], [4]. Within the present article, attention will focus on carbon fiber-reinforced composites.

\section{Fiber-Reinforced Composites}

The fibers, which have high strength and modulus, are embedded in a matrix which bonds them together, distributes the load from one fiber to another one and protects them from damage, to form fibrous composites [3], [5].

The mechanical characteristics of a fiber-reinforced composite are determined by the properties of the fibers: type, volume fraction, length, orientation. But also, by the properties of the matrix and the bounding between them. All these points will determine the density, tensile strength and modulus, 
compressive strength and modulus, fatigue strength and fatigue failure mechanisms, electrical and thermal conductivities and cost of a composite [1], [3]-[5].

\subsection{Composite Material Classification}

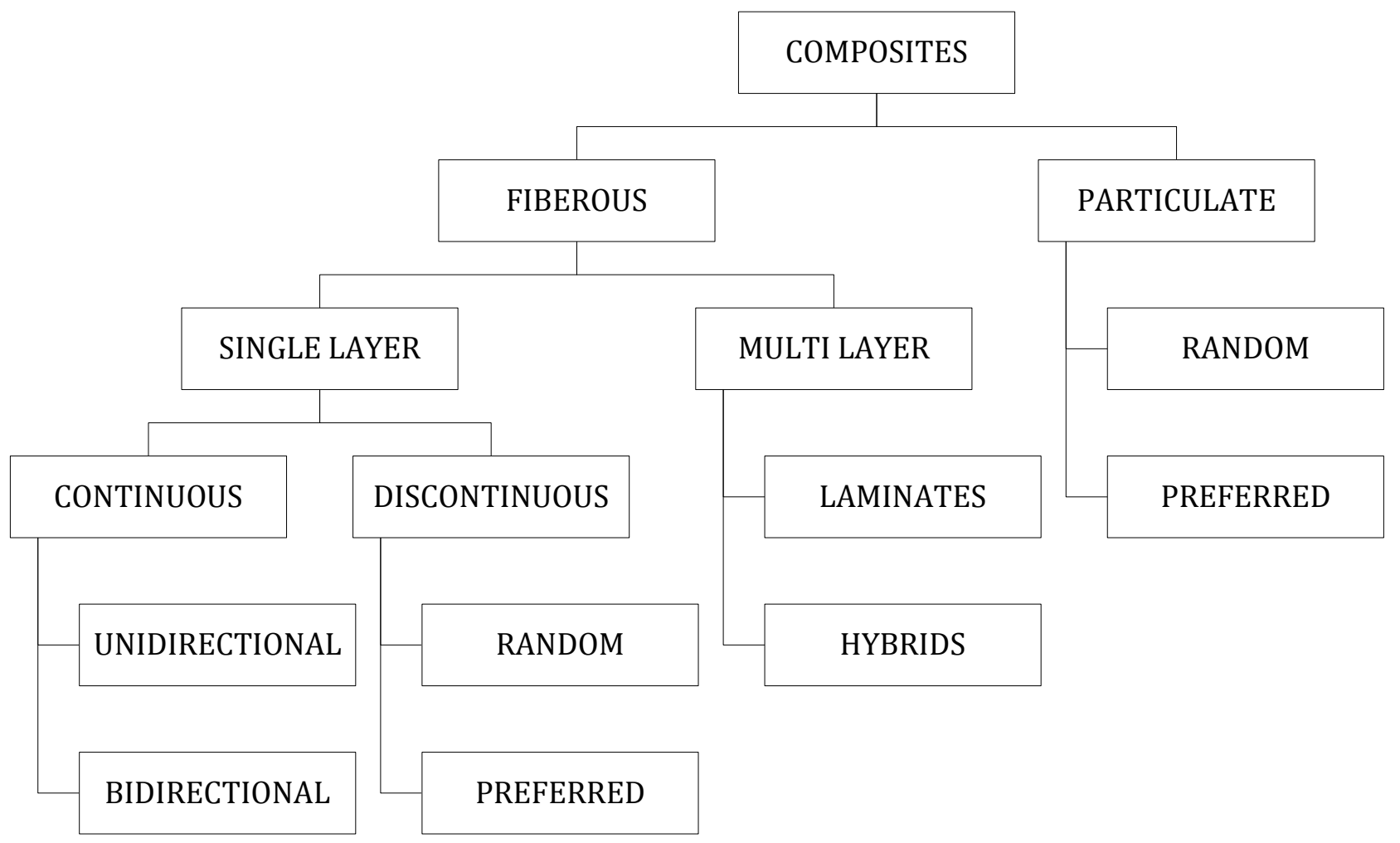

Figure 1. Composite Material Classification [3]

As showed on Figure 1, the fibrous composites can be further classified as single-layer composites or multilayer composites. Single-layer may be made from many layers if they have the same orientation and properties. The multilayer consists of several layers where each layer is a single-layer composite and its orientation is varied [1]-[3]. They can be classified as either discontinuous (short fiber composites) and or continuous (long fiber composites), depending on the length of the fibers. Short fiber composites normally have a random orientation, which reduces their strength and modulus, but usually they are less costly than the long fiber composites, which generally have a preferred orientation (unidirectional or bidirectional), being used where higher strength and stiffness are required [3], [4]. The typical reinforcements types are shown on Figure 2: 


\section{UNIDIRECTIONAL}

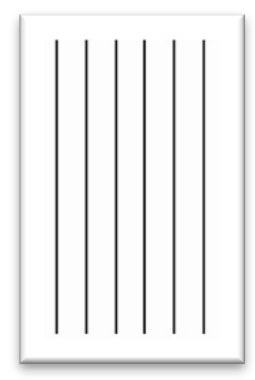

$0^{0}$

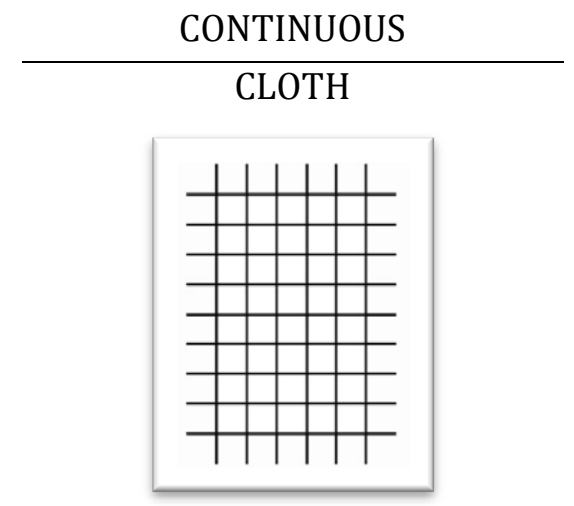

$0^{\circ} / 90^{\circ}$

\section{ROVING}

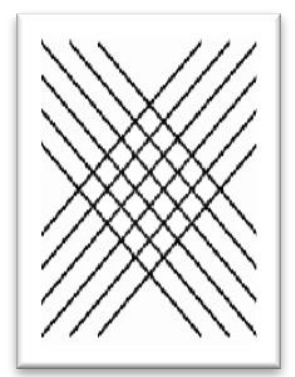

$\pm 30^{\circ}$

\section{DISCONTINUOUS}

ALIGNED

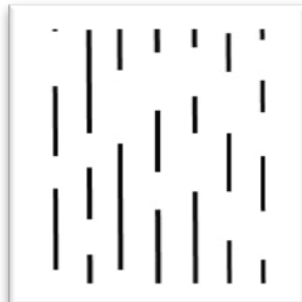

RANDOM

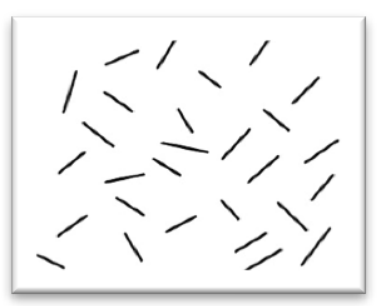

Figure 2. Typical Reinforcement Types [4]

Three types of fiber reinforcements are in common use in polymer matrix composites: carbon fibers, glass fibers and synthetic polymeric fibers [2]. Within the present article, attention will focus on carbon fibers.

\subsection{Carbon Fiber}

Carbon fiber, sometimes known as graphite fiber, refers to fibers which are at least $92 \mathrm{wt} . \%$ carbon in composition [6]. This material has the potential to replace steel and is popularly used in specialized, high-performance products. It is strong, stiff, lightweight enabling reinforcement used in the fabrication for improved performance in many applications, like aircrafts, racecars and sporting equipment [3], [5]-[8]. The reasons for this are: the highest specific modulus and specific strength of all reinforcing fiber materials; they retain their high tensile modulus and high strength at elevated temperatures; at room temperature, carbon fibers are not affected by moisture or a wide variety of solvents, acids, and bases. These fibers exhibit a diversity of physical and mechanical characteristics, allowing composites incorporating these fibers to have specific engineered properties, fiber and composite manufacturing processes have been developed that are relatively inexpensive comparing to other processes [1]. However, use of carbon fiber composites in cost-sensitive, high-volume industrial 
applications such as automobiles, wind energy, oil and gas, and infrastructure is limited because of today's relatively high price [7], [8].

To make carbon-based fibers, you begin with a precursor fiber. Carbon fibers are made from three different organic precursor materials: polyacrylonitrile (PAN), pitch or rayon. Currently, PAN precursor fibers are most commonly used [1]-[3], [5], [6], [9]. Polyaclylonithile based fibers offer good strength and modulus values, and excellent compression strength for structural applications [9].

The mechanical properties are not much affected by the type of precursor. However each one has a specific processing technique [2].

The process by which PAN is converted to carbon fibers (Figure 3) is part chemical and part mechanical. It involves, basically, the following steps [2], [3], [5], [6]:

1. The process starts by drawing long strands of precursor fibers.

2. The precursor is washed and stretched.

3. Stabilization: The stretched filaments are heated in air between $200^{\circ} \mathrm{C}$ and $300^{\circ} \mathrm{C}$, in multiple ovens, for a few hours. At this stage the material becomes flame resistant and gradually turns from white to black.

4. Carbonization: The fibers are heated to a very high temperature (up to $1000^{\circ} \mathrm{C}$ ) in an inert atmosphere. It is the process of pyrolyzing stabilized PAN fibers to expel most non-carbon atoms from the fibers. During the carbonization the high mechanical properties are developed.

5. Graphitization: Graphitization occurs by heating the carbonized fiber to high temperature (up to $3000^{\circ} \mathrm{C}$ ) in an inert atmosphere. The tensile modulus of elasticity of the fiber is improved during this stage.

6. After graphitization, special coating materials, called sizings, are applied to the fiber surface. Sizings, or fiber surface treatments, are used to provide lubrication and to protect the fibers during subsequent processing and handling. Other chemicals are also applied during the sizing operation to assist in bonding the fibers to the matrix.

7. The carbon fibers are dried and packaged, typically by spooling to make bobbins.

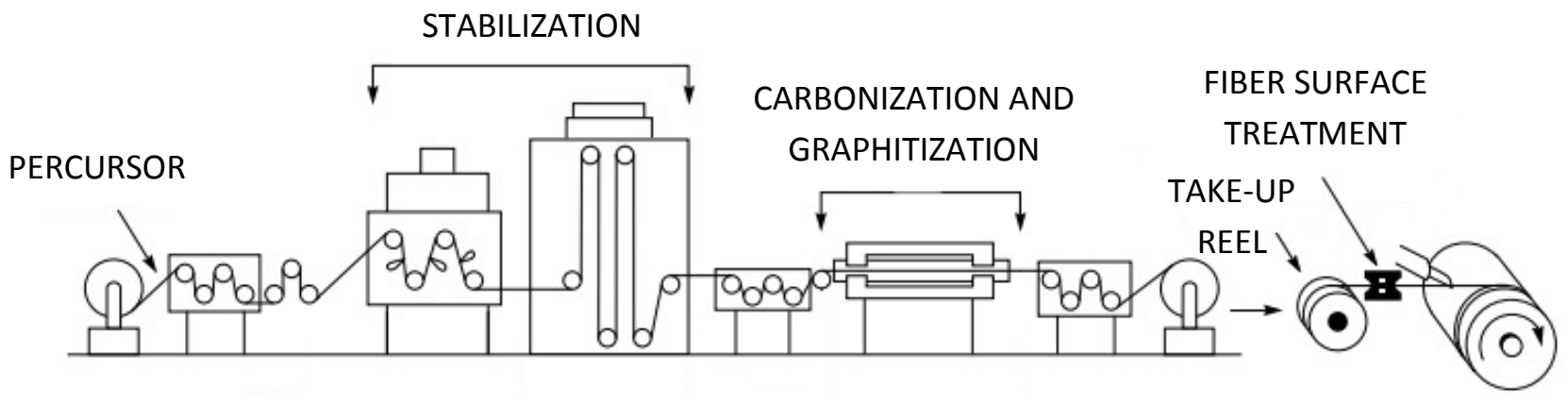

Figure 3. Continuous Production of Carbon Fiber from PAN Precursor 


\subsection{Matrix}

The matrix material has a few obligations to perform: it transfers load between the fibers, it protects the notch sensitive fibers from abrasion and it frames a defensive boundary between the filaments and environment. As a protective barrier, it prevents attack from moisture, chemicals and oxidation. It likewise assumes role in providing shear, transverse tensile and compression properties to the composite. The behavior of the composite under the impacts of temperature is likewise governed by the matrix performance [10].

Plastic matrices for fiber composites generally can be separated into two comprehensively classes: thermoplastics and thermosetting polymers. In both cases, curing involves the generation of a threedimensional cross-linked molecular structure [11].

The thermosets cannot be melted after the crosslinks are formed. They are molded by blending the resin, usually a liquid at room temperature, with different additives and the reinforcements. Then the mixture is placed into a mold where it is heated so that the crosslinks form. Thermoplastics are usually solids at room temperature. They are warmed, mixed with additives and reinforcements, and then placed into a mold and cooled to solidify. Thermoplastics can be melted again because no crosslinks are formed [12].

Main characteristics of both matrices are shown on Table 1.

\begin{tabular}{|l|l|}
\hline \multicolumn{1}{|c|}{ Thermosets } & \multicolumn{1}{c|}{ Thermoplastics } \\
\hline Undergoes chemical change when cured & Non-reacting, no cure required \\
\hline Low strain to failure & High strain to failure \\
\hline Low fracture energy & High fracture energy \\
\hline Processing is irreversible & Processing is reversible \\
\hline Very low viscosity possible & Very high viscosity \\
\hline Absorbs moisture & Absorbs little moisture \\
\hline Highly resistant to solvents & Limited resistance to organic solvents (some cases) \\
\hline
\end{tabular}

Table 1. Thermoset \& Thermoplastics Matrices Characteristics [13].

Is imperative to understand that these differences impact directly in the performance of the composite, for this, Table 2 will show some general advantages of each option and Table 3 the disadvantages.

\begin{tabular}{|l|l|}
\hline \multicolumn{1}{|c|}{ Thermosets } & \multicolumn{1}{c|}{ Thermoplastics } \\
\hline Relatively low processing temperature & Short processing times possible \\
\hline Good fiber wetting & Reusable scrap \\
\hline Formable into complex shapes & Post-formable can be reprocessed \\
\hline Liquid-resin manufacturing feasible & Rapid processing \\
\hline Resistant to Creep & Unlimited shelf life without refrigeration \\
\hline & High delamination resistance \\
\hline
\end{tabular}

Table 2. Thermoset \& Thermoplastics Matrices - Advantages [13] 


\begin{tabular}{|l|l|}
\hline \multicolumn{1}{|c|}{ Thermosets } & \multicolumn{1}{c|}{ Thermoplastics } \\
\hline Long processing time & Lower resistance to solvents \\
\hline Long $(\sim 1 \sim 2 \mathrm{~h})$ cure & Requires high temperature $\left(300-400^{\circ} \mathrm{C}\right)$ and pressure processing \\
\hline Restricted storage life & Can be prone to creep \\
\hline Requires refrigeration & Very poor drapability and tack \\
\hline
\end{tabular}

Table 3. Thermoset \& Thermoplastics Matrices - Disadvantages [13].

As said, Thermosets are the focus on this article, for so, the following details about the polymer matrix will contain only information about the Epoxy Resin utilized in the tests.

\subsubsection{Epoxy Resin}

Of all thermosetting resins, epoxy resins are the most widely used in aircraft structures. Epoxies have outstanding chemical and mechanical properties, have low shrinkage, and adhere adequately to most types of fiber [13]. This adhesion to the fiber, physical properties, elevated temperature performance, and its environmental resistance must also be considered. Epoxies excel in these categories up to moderately high temperatures (ca. $200^{\circ} \mathrm{C}$ ) [14]. Epoxy is by far the most widely used polymer matrix for carbon fibers. Trade names of epoxy include Epon, Epi-rez, and Araldite. For this, Epoxy, combining this excellent mechanical properties and corrosion resistance, with its already said, dimensional stability is relatively inexpensive, as Chung [6] confirm along with the others, compared to others resins.

In fields where advanced composites are used and properties are at a premium, epoxies are the foremost resin. Usually, the epoxy polymers are highly aromatic so that the advantages of strength and stiffness can be used in the composite part [12].

Epoxy resins are particularly versatile and can be formulated in a range of properties to serve as matrix materials for FRP (Fiber Reinforced Polymers) composites or to serve as adhesives. The epoxies used as the resins in FRP parts for structural engineering belong to the same family as the more familiar epoxies currently used in a variety of structural engineering applications, such as for concrete crack injection, as anchors for concrete, and for bonding precast concrete elements. Epoxy resins are known for having excellent corrosion resistance and undergoing significantly less shrinkage than polyester or vinylester resins when cured. Consequently, they are less prone to cracking under thermal loads [15].

Epoxy resins have been the thermosetting resins of choice in the aerospace industry for the last 50 years. In many aerospace applications, epoxy resin composites are postcured at elevated temperatures to raise their glass transition temperatures and to improve their physical and mechanical properties [15].

\section{Manufacturing e Processes}

One of the biggest challenges of all industries is improving manufacturing processes, and in composites field it is not different. The mechanical properties are the main reason for a composite to 
be chosen and the aim of the manufacturing method is naturally to enhance those properties. After a careful analysis and research, it was clear that two main fabrication methods are the most used due to their advantages and low requirement of investment: hand lay-up and vacuum infusion [16], [17].

Moreover, as the method of fabrication is mainly regarded to the improvement of the composite mechanical properties. And, the strengthening mechanism of the composite is directly connected to the geometry of the composite. Those chosen methods will deliver the desired geometry for this project, which in the classification of the composites materials it is going to be laminate, as in Figure 4 [18].

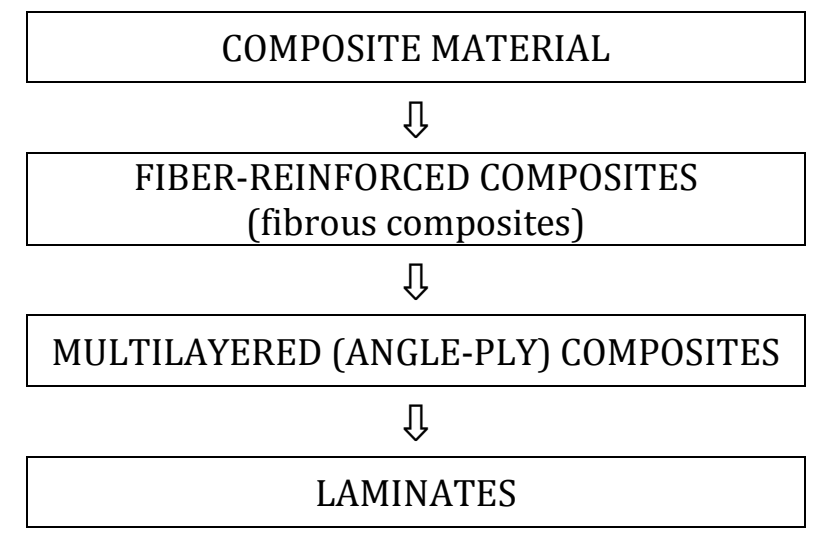

Figure 4. Classification of Composite Materials

Both methods will delivery laminate geometries, which basically is a carbon reinforced flat sheet. This type of geometry brings some advantages to the reinforcement because, usually, the fibers are disposed on woven form $\left(0^{\circ}\right.$ e $\left.90^{\circ}\right)$, which makes the application much more reliable and strong in case of tensile demanding events, in both directions, as in Figure 5 [2].

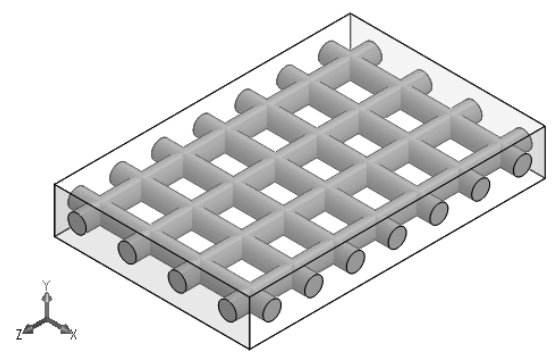

Figure 5. Lamina with Woven Fibers.

Bellow it will be discussed the main advantages and steps of the chosen processes to be performed in this project.

\subsection{Hand Lay-up Method}

As stated by Bhagwan et al (2006), the hand lay-up method is the simplest to perform, most common used and the oldest method of manufacturing for fiber reinforcement. Also, hand lay-up is suggested to use when the shape of the mould is complex, or the shape is big or has difficult corners to be reached. Furthermore, this technique is the best to apply where the volume of production is low [18]. 
The process of manufacturing with hand lay-up is quite simple and replicable to any other fiber reinforcement. On a mould, or in a flat surface that is the case of this project, the first step is to spread a releasing agent, so it makes easier to remove the finished product when it is done. Secondly, a gel coat brings a good surface finish, then, the carbon fiber reinforcement can be applied as many times as it is desired, depending on the wished thickness for the product. And, every layer applied, the resin has to be applied onto it. Also, a roller is used to spread the resin and the curing process can be done in room temperature, or in an oven, as desired.[16]

\begin{tabular}{ll} 
& \multicolumn{1}{l}{ Resin } \\
Carbon Reinforced Fiber Fabric \\
Gel Coat \\
Releasing Agent \\
Mould
\end{tabular}

Figure 6. Manufacturing process of hand lay-up schematic of layers. [16]

\subsection{Vacuum (Resin) Infusion}

The vacuum infusion, also called by resin infusion, is a versatile technique. This process requires a few more steps than the last method, however, this method is quite similar to hand lay-up and has some advantages that justify the effort. For instance, one of the advantages is the usage of a vacuum bag, and a vacuum pump, that at the same squeeze the excess resin out of the system and delivers an excellent surface finish [16], [17].

For this current project, it is going be a flat surface mould. So, onto the mould, firstly, a releasing agent is applied, then, the carbon reinforcement fabric, peel-ply fabric to make easier to pull it from the mould, a breathable fabric, so the resin can spread easily, and finally, the vacuum bag to make a vacuum environment system with the assistance of a vacuum tape, to seal all around the mould. Besides all those steps to prepare the mould, outside there is a whole system assembled, as shown the Figure 7, bellow [9].

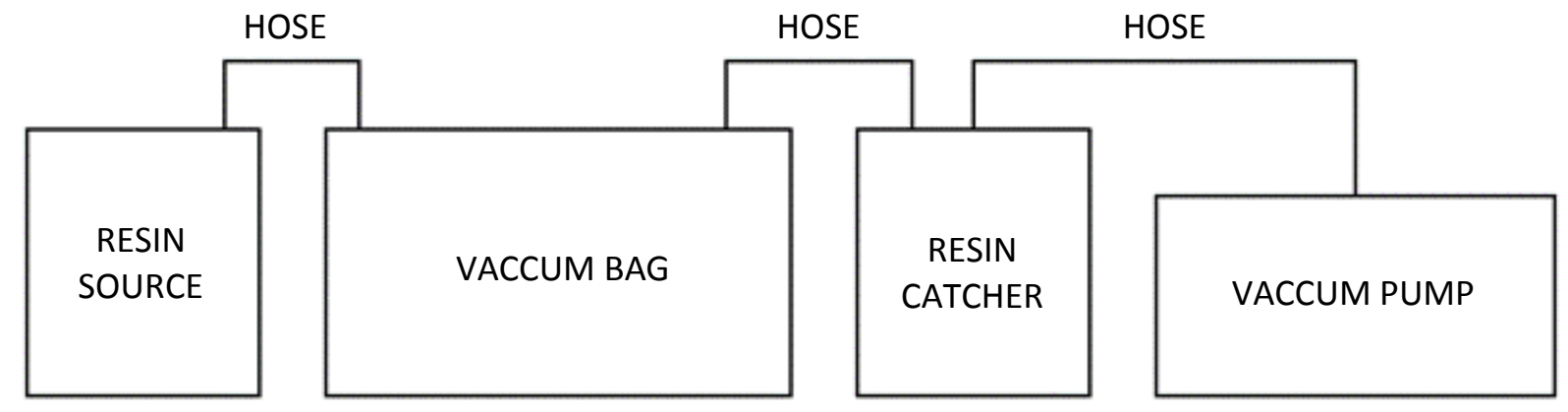

AIR FLOW

Figure 7. Manufacturing process of a vacuum infusion schematic.[19] 
As it is shown in the schematic image above, starting from the left to right, there is a resin source connected to a hose, then, a valve that is taking the resin into the mould. After that, at the other side of the mould there is another valve connected to another hose which is connect to a resin catcher bucket, and lastly, a vacuum pump, which is an essential equipment for this method [20].

\section{Carbon Fiber Sheet Manufacturing - Hand Lay-up}

For the first phase of the project, the manufacturing of a carbon fiber sheet was made in the laboratory of the university, as it is shown in the Figure 6 below. The method used was the hand lay-up, and, it was performed for all members of the group project.

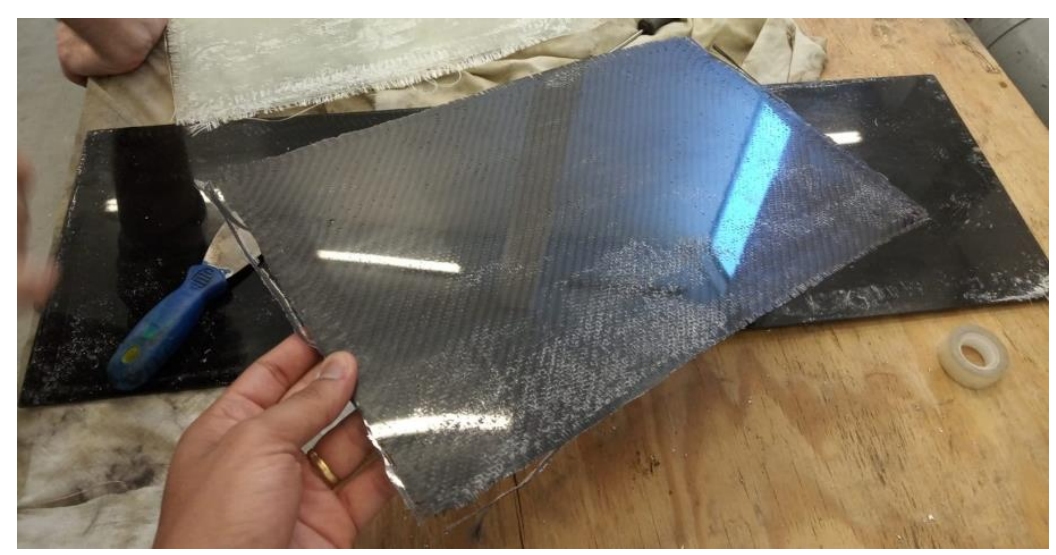

Figure 6. Carbon Fiber sheet manufactured in the laboratory of the University of Debrecen.

In total, it was used four (4) layers of carbon fiber fabric to make a sheet of thickness of about 1,5mm.

\section{Future Work Suggestions}

For the second phase of the project, it is suggested:

- To create the CAD model according to the layers and fiber direction defined;

- To define and carry out the best available laboratory tests (Tensile strength, etc...);

- To replicate the laboratory tests using the most suitable FEM analysis, as made by Mankovits [21] and Huri [22];

- To make a behaviour equation modelling, as made by Mattos at reference [23];

- To develop a finite element code that could be used for the rapid and approximately calculation of a specific part in a real situation to find different geometries while the material characteristics remain the same, optimizing the process , as made by Mankovits [24], [25];

\section{References}

[1] W. D. Callister, Materials science and engineering: an introduction, 7th ed. New York: John Wiley \& Sons, 2007. 
[2] M. W. Hyer, Stress analysis of fiber-reinforced composite materials, Updated edition. Lancaster, Pennsylvania: DEStech Publications, Inc, 2009.

[3] B. D. Agarwal, L. J. Broutman, and K. Chanshekhara, Analysis and performance of fiber composites, Fourth edition. Hoboken, New Jersey: Wiley, 2018.

[4] F. C. Campbell, Structural composite materials. Materials Park, Ohio: ASM International, 2010.

[5] P. K. Mallick, Fiber-reinforced composites: materials, manufacturing, and design, 3rd ed., [expanded and rev. ed.]. Boca Raton, FL: CRC Press, 2008.

[6] D. D. L. Chung, Carbon fiber composites. Boston: Butterworth-Heinemann, 1994.

[7] 'https://www.energy.gov/articles/top-9-things-you-didn-t-know-about-carbon-fiber', Energy.gov.

[8] 'https://web.ornl.gov/sci/manufacturing/research/carbon-fiber/'.

[9] 'http://www.mdacomposites.org/mda/psgbridge_CB_print_materials.h', p. 21.

[10] J. L. Clarke and European Structural Polymeric Composites Group, Eds., Structural design of polymer composites: EUROCOMP design code and handbook, 1. ed. London: E \& FN Spon, 1996.

[11] B. Ellis, Chemistry and technology of epoxy resins. 2015.

[12] A. B. Strong, Fundamentals of composites manufacturing: materials, methods and applications, 2nd ed. Dearborn, Mich: Society of Manufacturing Engineers, 2008.

[13] A. A. Baker, S. Dutton, and D. Kelly, Eds., Composite materials for aircraft structures, 2nd ed. Reston, VA: American Institute of Aeronautics and Astronautics, 2004.

[14] C. A. May, Ed., Epoxy resins: chemistry and technology, 2nd ed., rev. And expanded. New York: M. Dekker, 1988.

[15] L. C. Bank, Composites for construction: structural design with FRP materials. 2010.

[16] A. B. Strong, Fundamentals of composites manufacturing: materials, methods and applications, 2nd ed. Dearborn, Mich: Society of Manufacturing Engineers, 2008.

[17] C. D. Rudd and Society of Automotive Engineers, Eds., Liquid moulding technologies: resin transfer moulding, structural reaction injection moulding and related processing techniques. Cambridge: Woodhead Publ, 1997.

[18] A. Bhagwan, B. Lawrence, and C. K., Analysis and Performance of Fiber Composites, 3rd Ed. New Delhi: Wiley, 2006.

[19] Carbon by Design, 'Why Vacuum Infusion is often the correct choice.', Vacuum Infusion (VARTM). .

[20] A. HAMMAMI and B. R. GEBART, 'Analysis of the Vacuum Infusion Molding Process', vol. 21, 2000.

[21] T. Mankovits and T. Szabó, 'Finite Element Analysis of Rubber Bumper Used in Air-springs', Finite Element Analysis of Rubber Bumper Used in Air-springs, 2012.

[22] D. Huri and T. Mankovits, 'Comparison of the material models in rubber finite element analysis', IOP Conf. Ser.: Mater. Sci. Eng., vol. 393, p. 012018, Aug. 2018.

[23] H. S. da Costa Mattos, J. F. S. Brandão, F. C. Amorim, P. V. S. Araújo, and J. M. L. Reis, 'A unified expression to estimate the stress-strain curve of polyamides at different temperatures', Mater. Res. Express, vol. 6, no. 1, p. 015304, Oct. 2018.

[24] T. Mankovits, T. Szabó, I. Kocsis, and I. Páczelt, 'Optimization of the Shape of Axi-Symmetric Rubber Bumpers', Strojniški vestnik - Journal of Mechanical Engineering, vol. 60, no. 1, pp. 61-71, Jan. 2014. 
International Journal of Engineering and Management Sciences (IJEMS) Vol. 4. (2019). No. 4 DOI: 10.21791/IJEMS.2019.4.5.

[25] T. Mankovits, I. Kocsis, T. Portik, T. Szabó, and I. Páczelt, 'Shape design of rubber part using FEM', International Review of Applied Sciences and Engineering, vol. 4, no. 1, pp. 85-94, Jun. 2013. 